\title{
SÍNTESE E CARACATERIZAÇÃo DE NANOPARTÍCULAS DE PRATA
}

\author{
J. C. B. ALMEIDA ${ }^{1 *}$, S. M. PALÁCIO ${ }^{2}$, L. K. FERREIRA ${ }^{3}$, M. T. M. DEON ${ }^{4}$, E. A. \\ CAMPOS $^{5}$, K. C. KERBER ${ }^{6}$. \\ ${ }^{1}$ Universidade Estadual do Oeste do Paraná- Campus Toledo/ Mestrando Engenharia \\ Química \\ ${ }^{2,5}$ Universidade Estadual do Oeste do Paraná- Campus Toledo/ Docente adjunto \\ Engenharia Química \\ ${ }^{3,4,6}$ Universidade Estadual do Oeste do Paraná- Campus Toledo/ Graduando em \\ Engenharia Química. \\ *e-mail: eng.jeancarlos@live.com
}

\begin{abstract}
RESUMO
A nanotecnologia é uma área do conhecimento que começou a ser explorada neste século e apresenta receptividade em vários segmentos industriais devido às propriedades distintas das nanopartículas e melhorias que elas proporcionam a materiais. Apesar disso, algo pouco explorado são as propriedades nocivas que estas podem exercer sobre os seres vivos. Por exemplo, as nanopartículas de prata (nAg) apresentam propriedades bactericidas e vem sendo utilizadas para aplicação em roupas, cateteres, recheios de filtros e etc. Este trabalho teve como objetivo a síntese e a caracterização de nAg obtidas por diferentes rotas sintéticas estabelecidas pela literatura. As nAgs obtidas foram caracterizadas através da espectroscopia de absorção no UV-vis e pela técnica de espalhamento de luz dinâmico (DLS). As partículas obtidas nas reações A, B, C e D apresentaram diâmetro médio entre 10 a $14 \mathrm{~nm}$ uma vez que todas absorvem nos comprimentos de onda entre 395 a $405 \mathrm{~nm}$. O tamanho real médio das partículas das reações B e E, obtido através do método DLS, foi de 10,82 $\mathrm{nm}$ para a reação $\mathrm{B}$ e $2,58 \mathrm{~nm}$ para a reação $\mathrm{E}$.
\end{abstract}

\section{INTRODUÇÃO}

\subsection{Nanotecnologia}

A nanotecnologia estende a ciência de materiais para o domínio de partículas e interfaces com dimensões extremamente pequenas, da ordem de um a cem nanômetros. Partículas deste tamanho, ou "nanopartículas", apresentam uma grande área superficial e, frequentemente, exibem propriedades mecânicas, ópticas, magnéticas ou químicas distintas de partículas e superfícies macroscópicas. O aproveitamento dessas propriedades em aplicações tecnológicas forma a base da nanotecnologia de materiais (QUINA, 2004).

A nanotecnologia representa um moderno e inovador aproximar para desenvolver e testar novas formulações à base de nanopartículas metálicas com propriedades antimicrobianas (Duran et al., 2010).

A palavra nano, derivada do grego “anão", é usada para designar um bilionésimo 
de metro e pode ser representado pela notação $10^{-9} \mathrm{~m}$ (metro) ou $1 \mathrm{~nm}$ (um nanômetro) (ESTEVES et al., 2004)

Indiscutivelmente, a nanotecnologia é uma das áreas da ciência que mais vem se desenvolvendo atualmente, fruto dos altos investimentos em pesquisa, sendo os maiores investidores e com maior nível de desenvolvimento os Estados Unidos, seguidos da Alemanha e Japão (PASCHOALINO et al.,2010); (ZANETTI e CRECZYNSKI, 2008). De acordo com ROCCO (2001), a produção industrial anual deverá exceder a um trilhão de dólares, entre 2010 e 2015, requerendo aproximadamente dois milhões de trabalhadores. A nanociência e nanotecnologia servem de base para $o$ desenvolvimento de muitos estudos, por meio do controle da estrutura atômica da matéria, e dessa forma, revolucionam o modo pelo qual materiais e produtos são criados, além de possibilitar utilizações nunca antes imaginadas (NAVA, 2010).

\subsection{Aplicações das nanopartículas}

O uso das nanopartículas está presente nas mais variadas áreas e produtos de consumo, como na fabricação de dispositivos eletrônicos, aditivos alimentares, produtos antibacterianos, engenharia de tecidos (LIU et al., 2011), na fabricação de embalagens (CHEN et al, 2006), em produtos de higiene pessoal, cosméticos e perfumes (MENARD et al., 2011), na medicina, no segmento de imagens em diagnósticos (CORMODE et al, 2010), também em pesquisas biológicas, como na detecção de biomoléculas em ensaios de DNA, imunoensaios e bioimagem celular (GARCIA, 2010; LIU, 2006), assim como nanocarreadores de agentes terapêuticos que atuam na liberação de fármacos e genes (BRIGGER et al., 2002); (FADEEL e GARCIA, 2010); (FARAJI e WIPF, 2009).

Outra grande aplicação da nanotecnologia consiste nas novas formulações para o diagnóstico e tratamento do câncer, com o objetivo de aprimorar os métodos de detecção de tumores a aumentar a eficácia dos medicamentos utilizados atualmente (FERRARI, 2005).

Devido a sua potente atividade bactericida, este material vem sendo incorporado em diferentes produtos comerciais na área médico-hospitalar, como tecidos e implantes, sapatos e tênis, recipientes para armazenamento de alimentos, máquinas de lavar roupas, aparelhos de ar condicionado e até em creme dental. Também pode ser encontrado em próteses ósseas, instrumentos cirúrgicos, dentre muitos outros (CHEN e SCHLUESENER, 2008).

A prata em escala macroscópica não apresenta efeito nocivo ao ser humano, salvo em casos de exposição anormais. Estudos recentes demonstraram que estas partículas quando inaladas podem ser bioacumuladas no cérebro, e quando absorvidas pela pele podem ocasionar danos a estruturas celulares fundamentais, como as mitocôndrias (CHEN e SCHLUESENER., 2008).

\subsection{As Nanopartículas e o meio Ambiente}

Apesar das perspectivas animadoras sobre os benefícios da nanotecnologia, a discussão sobre nanotoxicologia tem ganhado espaço na comunidade científica, como uma resposta a uma necessidade de mais informações, especialmente com relação à segurança desses materiais. A toxicologia dos nanomateriais torna-se uma nova fronteira em toxicologia das partículas, uma vez que, nosso conhecimento atual sobre os potenciais efeitos adversos das nanopartículas ainda é pequeno (STERN e MCNEIL, 2008).

É crescente a preocupação sobre a segurança de nanopartículas para os seres humanos e para o ambiente implicando em que os eventuais riscos ambientais dessas partículas terão de ser testadosem estudos regulatórios (TIEDE et al., 2008). 
Não há dúvida de que a nanotecnologia oferece a perspectiva de grandes avanços que permitam melhorar a qualidade de vida e ajudar a preservar o meio ambiente. Entretanto, como qualquer área da tecnologia que faz uso intensivo de novos materiais e substâncias químicas, ela traz consigo alguns riscos ao meio ambiente e à saúde humana (QUINA, 2004).

Devido ao tamanho nanométrico destas estruturas, a difusão ocorre facilmente na água e no solo, o que também dificulta sua remoção por técnicas de filtração comumente utilizadas. As características físico-químicas das nanopartículas podem também facilitar a entrada e o acúmulo nos organismos vivos. De modo geral, a biodisponibilidade, biodegradabilidade e toxicidade de novos nanomateriais devem ser evidenciadas (PASCHOALINO et al., 2010).

A liberação de nanopartículas para o meio ambiente pode acontecer durante a fabricação de produtos, através de acidentes de trabalho durante a produção, ou mesmo como resíduos.

Desta forma, este trabalho tem por objetivo o estudo das nanopartículas de prata por meio das diferentes rotas sintéticas e sua caracterização para posterior avaliação de toxidade do risco ambiental que estas oferecem.

\section{MATERIAIS E METODOS}

\subsection{Síntese de nanopartículas de Prata}

Neste trabalho, todas as soluções aquosas utilizadas nas sínteses de nanopartículas foram preparadas utilizando água destilada produzida pelo destilador da marca Quimis modelo Q-341-25.

As massas foram pesadas em balança analítica, com precisão de $0,1 \mathrm{mg}$. As agitações foram realizadas com o auxilio do agitador magnético.

\subsubsection{Reagentes utilizados}

Os reagentes utilizados para obtenção da síntese de nanopartículas foram de grau analítico: Álcool polivinílico (PVA); Borohidreto de sódio $\left(\mathrm{NaBH}_{4}\right)$; Carboximetilcelulose sódica (CMC); Citrato de sódio $\left(\mathrm{Na}_{3} \mathrm{C}_{6} \mathrm{H}_{5} \mathrm{O}_{7}\right)$ e Nitrato de prata, $\mathrm{AgNO}_{3}$.

\subsubsection{Preparação das nanopartículas de prata}

Foram utilizadas cinco rotas sintéticas para a produção de nanopartículas de prata, baseadas na redução química de sais pelos agentes borohidreto de sódio e citrato de sódio, baseados nos trabalhos de Lee \& Meisel (1982) e Turkevich et al. (1951), respectivamente.

A reação global proposta para reações de síntese utilizando como agente redutor o $\mathrm{NaBH}_{4}$ é apresentada na Reação 1.

$\mathrm{AgNO}_{3(\mathrm{aq})}+\mathrm{NaBH}_{4(\mathrm{aq})} \rightarrow \mathrm{Ag}_{\mathrm{g}}+\frac{1}{2} \mathrm{H}_{2(\mathrm{~g})}+\frac{1}{2} \mathrm{~B}_{2} \mathrm{H}_{6(\mathrm{~g})}+\mathrm{NaNO}_{3(\mathrm{aq})}$

Para a realização das sínteses usando o borohidreto de sódio, foram preparadas soluções do agente precursor $\mathrm{AgNO}_{3}$ em duas concentrações (Soluções P1 e P2), solução do agente redutor $\mathrm{NaBH}_{4}$ (Solução R) e soluções dos estabilizantes PVA e CMC (Soluções E1 e E2, respectivamente), conforme Tabela 1.

As reações foram conduzidas sob agitação constante em resfriamento com auxílio de gelo por um período de aproximadamente 20 minutos. Após este tempo, foi cessada a agitação e a reação foi retirada do resfriamento e o volume de solução resultante foi completado para 125 $\mathrm{mL}$ com água ultra-pura. As quantidades adicionadas de cada reagente nas sínteses denominadas A, B, C e D são apresentadas na Tabela 1. 


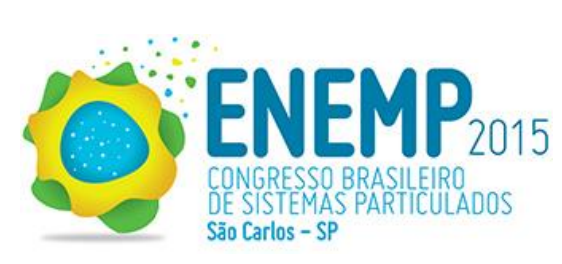

Tabela 1 - Resumo das quantidades de soluções adicionadas nas reações de redução de $\mathrm{AgNO}_{3}$ com $\mathrm{NaBH}_{4}$ e estabilizantes.

\begin{tabular}{cccccc}
\hline Solução & $\begin{array}{c}\text { Agente } \\
\text { Precursor } \\
(\mathrm{ml})\end{array}$ & $\begin{array}{c}\text { Agente } \\
\text { Redutor } \\
(\mathrm{ml})\end{array}$ & $\begin{array}{c}\text { Estabilizante } \\
(\mathrm{ml})\end{array}$ \\
\cline { 2 - 6 } & P1 & P2 & R & E1 & E2 \\
\hline A & - & 25 & 75 & - & 12,5 \\
B & 25 & - & 75 & 12,5 & - \\
C & - & 25 & 75 & 12,5 & - \\
D & 25 & - & 75 & - & 12,5
\end{tabular}

$\mathrm{P} 1=\mathrm{AgNO}_{3}\left(5,45 \times 10^{-3} \mathrm{M}\right) ; \mathrm{P} 2=\mathrm{AgNO}_{3}\left(2,99 \times 10^{-3}\right.$ $\mathrm{M}) ; \mathrm{R}=\mathrm{NaBH}_{4}\left(3,03 \times 10^{-3} \mathrm{M}\right) ; \mathrm{E} 1=\mathrm{PVA}(1 \%) ; \mathrm{E} 2=$ $\mathrm{CMC}(1 \%)$.

A síntese de nanopartículas de prata utilizando os agentes redutores citrato de sódio (conforme mostra a reação química 2 abaixo) e borohidreto de sódio, simultaneamente foi denominada de "E". Para realização desta síntese foram preparadas uma solução contendo o agente precursor $\mathrm{AgNO}_{3} \mathrm{e}$ o agente redutor $\mathrm{Na}_{3} \mathrm{C}_{6} \mathrm{H}_{5} \mathrm{O}_{7}$ (Solução PR1). Esta solução foi preparada pela dissolução de $0,0045 \mathrm{~g}$ de $\mathrm{AgNO}_{3}$ e $0,0078 \mathrm{~g}$ de $\mathrm{Na}_{3} \mathrm{C}_{6} \mathrm{H}_{5} \mathrm{O}_{7}$ em $100 \mathrm{~mL}$ de água. Foi preparada uma solução do agente redutor $\mathrm{NaBH}_{4}(\mathrm{R})$ na concentração $3,03 \times 10^{-3} \mathrm{~mol} \mathrm{~L}^{-1}$ :

A reação de síntese foi conduzida com adição de $3 \mathrm{ml}$ da solução $\mathrm{R}$ em $100 \mathrm{ml}$ da solução PR1, sob intensa agitação por um período de aproximadamente 3 minutos.

$$
\begin{aligned}
& 4 \mathrm{AgNO}_{3}+4 \mathrm{C}_{6} \mathrm{H}_{5} \mathrm{O}_{7} \mathrm{Na}_{3}+2 \mathrm{H}_{2} \mathrm{O} \rightarrow \\
& 4 \mathrm{C}_{6} \mathrm{H}_{5} \mathrm{O}_{7} \mathrm{H}_{3}+4 \mathrm{NaNO}_{3}+2 \mathrm{H}_{2} \mathrm{O}++
\end{aligned}
$$

\subsection{Caracterização das nanopartículas}

\subsubsection{Aspecto Visual e Espectro Uv-vis}

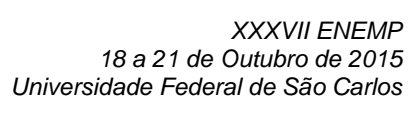

As soluções contendo as nanopatículas (A, B, C e D) foram detectadas visualmente através da coloração apresentada e por espectroscopia de absorção molecular. Foi utilizado um espectrofotômetro UV-Visível Shimadzu 1800 na faixa espectral entre 200 e $800 \mathrm{~nm}$. Para a leitura no espectrofotômetro as soluções foram diluídas em proporção 1/25 $(\mathrm{v} / \mathrm{v})$.

\subsubsection{Espalhamento de luz dinâmico (DLS)}

Os raios hidrodinâmicos médios das nanopartículas foram determinados por Espalhamento de Luz Dinâmico (Dinamic Light Scattering - DSL), partir da equação de Stokes-Einstein, utilizando o equipamento Zetasizer, Nano Series da Malvern Intruments.

Foram realizadas análises somente das reações denominadas " $B$ " e "E" pois o agente redutor difere entre elas.

2.2.3 Determinação da concentração por espectrofotômetro de Absorção atômica (AA)

Nas medidas de concentração de prata, na fase líquida foi utilizado um espectrofotômetro de absorção atômica, marca ParklinElmer modelo AAnalyst 700. Previamente à análise das amostras, foi feita curva de calibração, utilizando solução padrão de prata de 0 a $4 \mathrm{mgL}^{-1}$.

As medidas de absorbância foram feitas, utilizando lâmpada de $\mathrm{Ag}$, operando no comprimento de onde de $328,1 \mathrm{~nm}$ com vazão de gás Acetileno $2 \mathrm{~L} / \mathrm{min}$ e tamanho da fenda de $0,2 \mathrm{~nm}$.

Para a leitura no espectrofotômetro, as soluções foram diluídas em proporção 1/10 (v/v) para que as concentrações dos íons metálicos estivessem dentro do intervalo definido pela curva de calibração. As medidas foram realizadas em triplicata.

Após prévia calibração do equipamento utilizando padrão conhecido de $1000 \mathrm{mgL}^{-1}$, 
as concentrações de prata total foram determinadas.

\section{RESULTADOS E DISCUSSÃO}

3.1 Aspecto visual das soluções de nanopartículas de prata

No presente trabalho diferentes colorações foram obtidas para as cinco diferentes rotas sintéticas (Figura 1). Nas reações A e C observou-se uma dispersão coloidal amarela, em ambas a concentração de nitrato de prata utilizado foi a mesma, o que variou foi o estabilizante utilizado. Já nas reações $\mathrm{B}$ e $\mathrm{D}$ foi empregado um nitrato com maior concentração, verifica-se uma dispersão coloidal marrom escuro em B e castanho em D. A reação $E$ foi a que empregou o nitrato de menor concentração, a coloração observada foi ligeiramente menos intensa que as anteriores.

Figura 1 - Aspecto visual das soluções de nanopartículas de prata

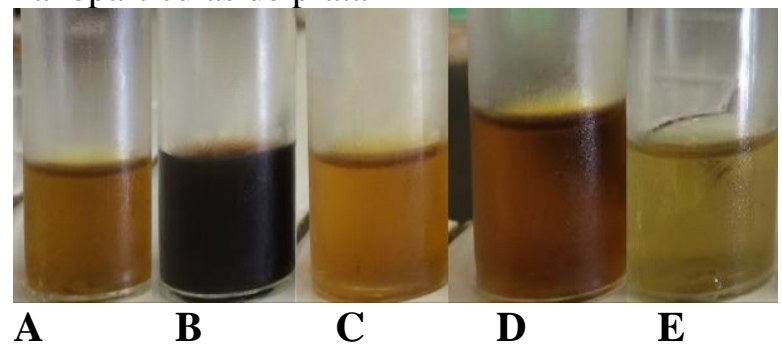

A cor amarela característica observada na prata coloidal é resultado da absorção da radiação eletromagnética em ressonância com os plasmons de superfície. Com o aumento das partículas de prata, a cor amarela característica da solução padrão passa para laranja e, posteriormente, violeta até atingir a coloração característica da prata em escala macroscópica. Esse fenômeno de diferença de coloração pode ser explicado pela adição de solução de nitrato de prata, que faz com que as partículas se aglomerem e se tornem maiores. (JUNIOR et al., 2013).
Segundo JIN et al. (2001), uma solução de $\mathrm{nAg}$ totalmente livre de aglomerados deve ter uma coloração amarela mais clara. Segundo experimentos realizados por outros autores dispersões com alta concentração de aglomerados se apresentavam bastante turvas. $\mathrm{O}$ que pode justificar a coloração bastante escura da reação B.

3.2 Caracterização das nanopartículas de prata: espectro UV-vis

Na Figura 2 podem ser observados que os picos obtidos para as reações A-E se encontram entre 390 e $405 \mathrm{~nm}$.

Figura 2 - Espectros eletrônicos das diferentes sínteses de $\mathrm{nAg}$

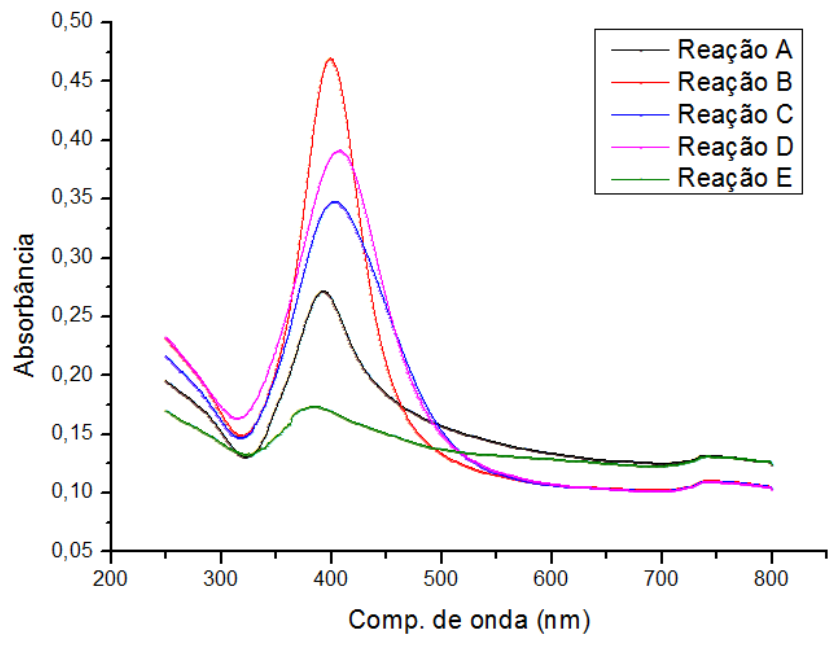

Por meio da Tabela 2 pode-se verificar os valores dos comprimentos de onda cada banda de absorção obtidas para as soluções AE. 
Tabela 2 - Valores dos comprimentos de onda obtidos para as soluções A-E

\begin{tabular}{cc}
\hline Solução & $\begin{array}{c}\text { Comprimento } \\
\text { de onda (nm) }\end{array}$ \\
\hline A & 396,0 \\
B & 399,5 \\
C & 404,0 \\
D & 394,5 \\
E & 390,5 \\
\hline
\end{tabular}

Segundo SEGALA et al., (2006), os comprimentos de onda máximos e largura da banda são dependentes do tamanho, da morfologia e da composição. As bandas são o resultado de uma combinação de absorção e espalhamento de luz devido às interações com o campo de plasmon.

De acordo com a teoria de Mie (KLABUNDE, 2001) apenas uma única excitação eletrônica em níveis quânticos é esperada no espectro de absorção de nanopartículas esféricas. O resultado prático da teoria de Mie é que para partículas de prata menores do que cerca de $40 \mathrm{~nm}$ de diâmetro, irá mostrar uma forte banda localizada na faixa entre 380 a $420 \mathrm{~nm}$.

$A$ reação $C$ apresentou $o$ maior comprimento de onda, o que indica que, comparando com as outras reações, seria a reação com maior agregação das partículas. Por meio da observação da coloração, esperava-se que a reação $B$ apresentasse maior agregação, entretanto, não foi o que ocorreu.

A Tabela 3 mostra a correlação entre o diâmetro médio das nanopartículas e o comprimento de onda observado para as bandas de maior absorção.

Tabela 3 - Tamanho médio das nanopartículas em relação ao comprimento de onda.

\begin{tabular}{cc}
\hline $\begin{array}{c}\text { Tamanho } \\
\text { partícula }(\mathrm{nm})\end{array}$ & $\begin{array}{c}\text { Comprimento } \\
\text { de onda }(\mathrm{nm})\end{array}$ \\
\hline $5-10$ & $380-390$ \\
$10-14$ & $395-405$ \\
$30-50$ & $420-435$ \\
\hline
\end{tabular}

Fonte: SOLOMON (2007)
Comparando os resultados obtidos (Tabela 2) com os valores apresentados na Tabela 3, fica evidente que o tamanho das nanopartículas das reações $\mathrm{A}, \mathrm{B}, \mathrm{C}$ e $\mathrm{D}$ encontram-se na faixa de 10 a $14 \mathrm{~nm}$, uma vez que todas possuem comprimento de onda entre 395 a 405nm. No entanto, a reação E possui nanopartículas de prata de tamanho entre 5 e $10 \mathrm{~nm}$ decorrentes de um comprimento de onda entre 380 e $390 \mathrm{~nm}$.

\subsection{Espalhamento de luz dinâmico (DLS)}

$\mathrm{Na}$ Figura 3 pode-se observar a distribuição do tamanho das nanopartículas obtida através do ensaio de DLS. Sendo que 99,9\% das partículas apresentam um diâmetro médio de $10,82 \mathrm{~nm}$ e $0,1 \%$ das partículas um diâmetro de 45,97.

Figura 3- Espalhamento de Luz dinâmico da Solução B.

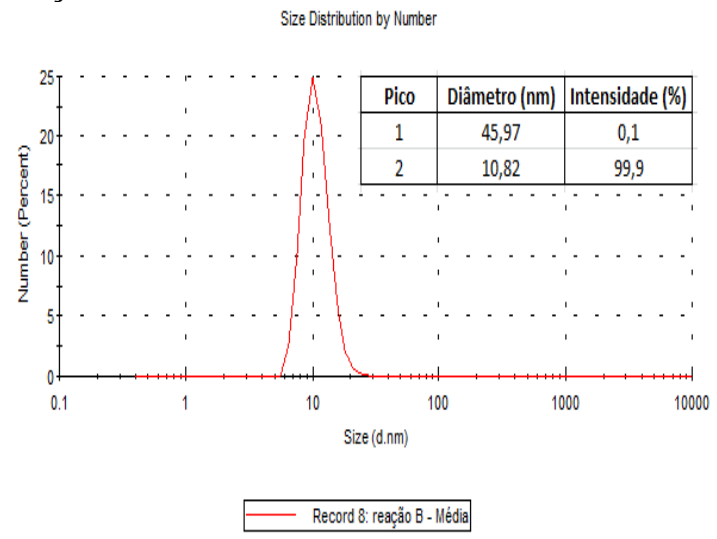

Esta técnica garante maior precisão no tamanho médio das partículas, o resultado apresentado confirmou o diâmetro médio obtido por meio da técnica do Uv-vis.

$\mathrm{Na}$ Figura 4 pode-se observar a distribuição do tamanho das partículas obtida através do ensaio de DLS da reação denominada E. Sendo que $100 \%$ das partículas apresentam um diâmetro médio de aproximadamente $2,6 \mathrm{~nm}$. 
Figura 4 - Espalhamento de Luz dinâmico da Solução E.

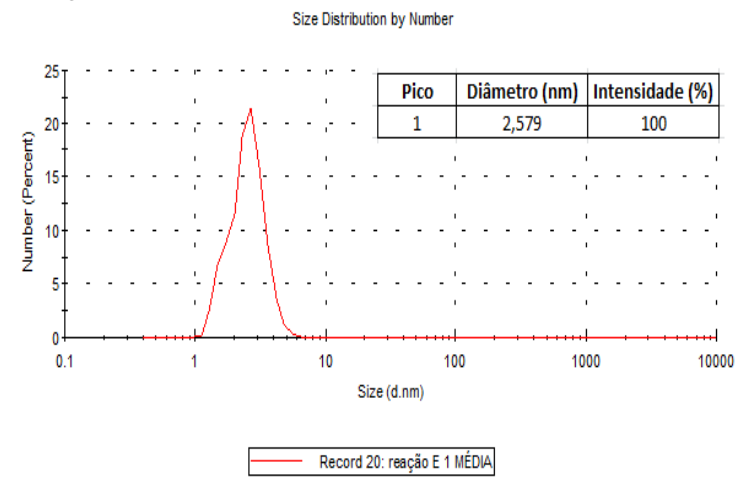

3.4 Determinação da concentração de $\mathrm{nAg}$ por espectrofotômetro de Absorção atômica (AA)

Analisando a Tabela 4 verifica-se que o aumento da concentração real determinada é diretamente proporcional ao aumento da concentração do agente precursor $\left(\mathrm{AgNO}_{3}\right)$, este aumento da concentração está ligado ao aumento da absorção.

Tabela 4 - Concentração real das sínteses de nAg (A,B,C,D,E) fornecida pela Absorção Atômica

\begin{tabular}{cc} 
Reações & Concentração Real $\left(\mathrm{mgL}^{-1}\right)$ \\
\hline A & 59,8060 \\
B & 113,1655 \\
C & 61,8616 \\
D & 111,9940 \\
E & 30,7085 \\
\hline
\end{tabular}

Araújo (2010) em seu estudo utilizou a absorção atômica para determinar a concentração de nanoparticulas de prata produzidas a partir de misturas de soluções contendo dodeciltrimetilamônio (Dotab) e sulfadiazina de prata (SAg). O Dotab agiu como agente redutor enquanto no presente trabalho empregou-se o borohidreto de sódio $\left(\mathrm{NaBH}_{4}\right)$ para esse fim. A concentração final das nanopartículas sintetizadas por Araujo, (2010) pôde ser estimada, sendo ela de 60 $\mathrm{mg} / \mathrm{L}$. Para fins de comparação, as reações A e C (Tabela 4) apresentaram um valor próximo, uma vez que para as duas pesquisas foram realizadas síntese de nanopartículas de prata diferenciando o agente redutor utilizado na síntese.

\section{CONSIDERAÇOES FINAIS}

Neste trabalho foram sintetizadas soluções de nAg por cinco rotas diferentes, o borohidreto de sódio foi utilizado como agente redutor em todas, variando o estabilizante, concentração do nitrato de prata e, em uma das reações, a presença do citrato de sódio.

As soluções obtidas foram caracterizadas pela técnica de UV-Vis e pelo aspecto visual. A concentração real foi determinada através da absorção atômica.

As análises de DLS mostraram a distribuição dos tamanhos das partículas na solução aquosa. Pode-se avaliar que, a reação B em análise apresentou uma distribuição de tamanho médio de partículas igual à 10,82 $\mathrm{nm}$, o que confirma o resultado do espectro de UV-Vis anteriormente comentado. Já a reação $\mathrm{E}$ apresentou uma distribuição de tamanho médio de partículas igual à 2,579 diferenciando do resultado obtido pelo uv-vis.

Foi clara a influência da concentração do precursor $\left(\mathrm{AgNO}_{3}\right)$ na coloração da solução final. Sendo que, quanto maior a concentração do nitrato de prata, mais intensa foi a coloração obtida. Além disso, o aumento da concentração do agente precursor influenciou diretamente no aumento da concentração real determinada pela absorção atômica.

Em relação ao UV-vis, todas as reações obtiveram um pico característico de nAg com valor semelhante, o que indica que todas as rotas podem ser consideradas satisfatórias, pois o tamanho das partículas não variou drasticamente entre as diferentes rotas. 


\section{NOMENCLATURA}

AA - Absorção atômica

AgNO3 - Nitrato de prata

CMC - Carboximetilcelulose sódica

Dotab - Dodeciltrimetilamônio

$\mathrm{HNO}_{3}$ - Ácido nitríco

$\mathrm{m}$ - Metro

mg - Miligrama

nm - Nanômetro

$\mathrm{mL}$ - Mililitro

$\mathrm{mg} / \mathrm{L}$ - Miligrama por litro

nAg - Nanopartículas de prata

$\mathrm{NaBH} 4$ - Borohidreto de sódio

$\mathrm{Na}_{3} \mathrm{C}_{6} \mathrm{H}_{5} \mathrm{O}_{7}$ - Citrato de sódio

PVA - Álcool polivinílico

SAg - Sulfadiazina de prata

UV-Vis - UV - Visível

\section{REFERÊNCIAS}

ARAÚJO, Emiliane Andrade. Caracterização físico-química e ação antimicrobiana de nanopartículas de prata obtidas por uma nova síntese. Viçosa - Minas Gerais, 2010. 96p. Tese (doutorado) - Programa de PósGraduação em Ciência e Tecnologia de Alimentos. Universidade Federal de Viçosa, 2010.

Brigger, I.; Dubernet, C.; Couvreur, P.; Nanoparticles in cancer therapy and diagnosis. Adv Drug Deliv Rev, v. 54, p. 631-651, 2002.

Chen, X.; Schluesener, H. J.; Toxicol. Lett. 2008, 176, 1 .

Chen, Z. et al. Acute toxicological effects of copper nanoparticles in vivo. Toxicology Letters, v. 163, p. 109-120, 2006.

Cormode, D.P. et al. Modified natural nanoparticles as contrast agents for medical imaging. Advanced Drug Delivery Reviews, v. 62, p. 329-338, 2010.

DURAN, Nelson; MARCATO Priscyla D.;CONTI, Roseli; ALVES, Oswaldo L.;COSTA, Fabio T. M.; BROCCHI, Marcelo. Nanotecnologia e o meio ambiente: perspectivas e riscos. Quim. Nova, Vol. 27, No. 6, 1028-1029, 2004.

E. Metcalfe, "Analytical Chemistry by Open Learning," Atomic Absorption and Emission Spectroscopy, John Wiley \& Sons, 1987.

Esteves, A.C.C.; Timmons, A.B.; Trindade, T.; Nanocompósitos de matriz polimérica: estratégias de síntese de materiais híbridos. Química Nova, v. 27, n. 8, 2004.

Fadeel, B.; Garcia-Bennett, A.E.; Better safe than sorry: Understanding the toxicological properties of inorganic nanoparticles manufactured for biomedical applications. Adv Drug Deliv Rev, v. 62, p. 362-374, 2010.

Faraji, A.H.; Wipf, P.; Nanoparticles in cellular drug delivery. Bioorganic \& Medicinal Chemistry, v. 17, p. 2950-2962, 2009.

Ferrari, M. Cancer nanotechnology: opportunities and challenges. Nat Rev Cancer, v. 5, 161-171, 2005.

GARCIA, M., V., D. Síntese, caracterização e estabilização de nanopartículas de prata para aplicações bactericidas em têxteis. 2011.

Garcia, M.B.F.; Imobilização de enzimas em materiais nanoestruturados: atividade, estabilidade e aplicação da peroxidase imobilizada em bicamadas lipídicas e nanopartículas poliméricas. Centro de Ciências Físicas e Matemáticas, Universidade Federal de Santa Catarina, Florianópolis, p. 154, 2010.

J. E. Cantle, "Techniques and Instruments in Analytical Chemistry - Volume 5," Atomic Absorption Spectrometry, 1982.

JIN, R.; CAO, Y. W.; MIRKIN, C. A.; KELLY, K. L.; SCHATZ, G. C.; ZHENG, J. G. PhotoInduced Conversion of Silver Nanospheres to Nanoprisms. Science, 94, 2001, 1901-1903.

JUNIOR, Maurício A. Melo; SANTOS, Lucas S. S.; GONÇALVES, Maria do C; NOGUEIRA, Ana Flávia. Preparação de 
nanopartículas de prata e ouro: um método simples para a introdução na nanociência em laboratório de ensino. Quim. Nova, Vol. 35, No. 9, 1872-1878, 2012.

KLABUNDE, K. J. - Nanoscale materials in chemistry, New York: John Wiley \& Sons, Inc., 2001;

LINK, S.; EL-SAYED, M. A. Optical properties and ultrafast dynamics of metallic nanocrystals. Annual Review of Physical Chemistry, v.54, p. 331-366, 2003.

Liu, Y. et al. Preparation and characterization of $\quad \alpha$-galactosidase-loaded chitosan nanoparticles for use in foods. Carbohydrate Polymers, v. 83, p. 1162-1168, 2011.

Menard, A.; Drobne, D.; Jemec, A.; Ecotoxicity of nanosized TiO2. Review of in vivo data. Environ Pollut, v. 159, p. 677-684, 2011.

Nava, A. Análise toxicológica de nanotubos de carbono de paredes múltiplas em camundongos prenhes. Centro Universitário Franciscano, Santa Maria, RS, p. 90, 2010.

Paschoalino, M.P.; Marcone, G.P.S.; Jardim, W.F.; Os Nanomateriais e a Questão Ambiental. Química Nova, v. 33, n. 9, 2010.

QUINA, Frank H. Nanotecnologia e o meio ambiente: perspectivas e riscos. Quim. Nova, Vol. 27, No. 6, 1028-1029, 2004.

Rocco, M.C. International trategy for nanotechnology research and development. Journal of Nanoparticle Research, v. 3, n. 8, 2001.

SEGALA, K.; DUTRA, R. L.; OLIVEIRA, E. M. N.; ROSSI, L. M.; PAULA, M. M. S.; FRANCO, C. V. Characterization of poly\{trans[RuCl2(vpy)4]-styrene-4vinylpyridine $\}$ impregnated with silver nanoparticles in non aqueous medium. Journal of the Brazilian Chemical Society, 17, 2006, 1679-1682.

SOLOMON, Sally; BAHADORY, Mozhgan; JEYARAJASINGAN, Aravindan; RUTKOWSKY, Susan; BORITZ, Charles. Synthesis and study of silver nanoparticles.
EUA: Journal of Chemical Education- Vol. 84 February 2007 No. 2 . p. 322

Stern, S.T.; McNeil, S.E.; Nanotechnology safety concerns revisited. Toxicol Sci, v. 101, p. 4-21; 2008.

TIEDE, Karen; HASSELLOV, Martin; BREITBARTH, Eike; CHAUDHRY, Qasim; BOXALL, Alistair B. A. Considerations for environmental fate and ecotoxicity testing to support environmental risk assessments for engineered nanoparticles. Journal of Chromatography A, 1216 (2009) 503-509.

TURKEVICH, J., STEVENSON, P., HILLIER, J. A study of the nucleation and growth processes in the synthesis of colloidal gold. Discussions of the Faraday Society, v. 11, p. 55-75, 1951.

Zanetti-Ramos, B.G.; Creczynski-Pasa, T.B.; $\mathrm{O}$ desenvolvimento da nanotecnologia: cenário mundial e nacional de investimentos. Revista Brasileira de Farmácia, v. 89, n. 6, 2008.

\section{AGRADECIMENTOS}

Agradecimento em especial a Capes/CNPq pelo apoio financeiro. 